\title{
Assessment of the nasal obstruction after endoscopic septoplasty compared with conventional technique by computed tomography and Nasal Surgical Questionnaire
} Ayat A. El Nasr ${ }^{\mathrm{a}}$, Mohamed A.M. Belih

\author{
Departments of a Otorhinolaryngology, \\ ${ }^{\mathrm{b}}$ Radiology, Faculty of Medicine, Al-Azhar \\ University, Cairo, Egypt \\ Correspondence to Ayat A. El Nasr, MSc, A \\ Zahraa Hospital, AlAbbasya, Cairo 11646, \\ Egypt Tel: +20 201006577 631; \\ e-mail: ayatnasr7419@yahoo.com \\ Received 8 May 2018 \\ Accepted 26 September 2018 \\ The Egyptian Journal of Otolaryngology \\ 2018, 34:272-277
}

\begin{abstract}
Background
Nasal obstruction is a common annoying symptom of septal deviation, and endoscopic septoplasty gives better illumination and accurate vision, and hence can provide markedly good dealing with posterior deviations, isolated spurs, and high deviations. Computed tomography (CT) scan and Nasal Surgical Questionnaire (NSQ) are important for accurate postoperative follow-up.

Objective

The aim of this study was to express our experience in the assessment of the nasal obstruction after endoscopic septoplasty compared with conventional septoplasty in patients with nasal septum deviation by measuring the size of the inferior turbinate with CT scan and measuring patient satisfaction by NSQ score.

Patients and methods

This was prospective study of 100 patients, complaining mainly of nasal obstruction. They were divided into two groups: group $A$, who underwent endoscopic septoplasty, and group B, who underwent conventional septoplasty. All the patients underwent septoplasty alone without inferior turbinate surgery. Preoperative and postoperative CT scan and NSQ were the basic documentation for the results.

Results

Endoscopic septoplasty showed a better reduction in nasal obstruction than conventional septoplasty; however, the postoperative reduction on the size of the inferior turbinate and NSQ score were highly significant in both groups $(P=0.001)$.

\section{Conclusion}

Both endoscopic and conventional septoplasty without turbinate surgery in patients with nasal septum deviation were effective in improving the nasal obstruction. However, endoscopic septoplasty had better results in improving nasal obstruction.

\author{
Keywords: \\ Questionnaire \\ Egypt J Otolaryngol 34:272-277 \\ (C) 2018 The Egyptian Journal of Otolaryngology \\ $1012-5574$
}

conventional septoplasty, deviated septum, endoscopic septoplasty, Nasal Surgical
\end{abstract}

\section{Introduction}

Chronic nasal obstruction is considered to be one of the most common symptoms of septal deviation [1]. The nasal valve is formed medially by the septum and laterally by the caudal edge of the upper lateral cartilage, and it accounts for $\sim 50 \%$ of total upper airway resistance. The anterior tip of the inferior turbinate is found in the nasal valve region, and hypertrophy can cause an increase in airway resistance [2]. Septal deviation surgery has undergone many modifications. First, submucous resection of the septum was the technique that was considered a radical surgery. Later, septoplasty was developed with minimal resection of the septum and fewer complications. After the wide use of the endoscope in the field of otolaryngology, endoscopic surgical correction of the nasal septum helped in removing only the deviated part, spur and maxillary crest. Endoscopic septoplasty is more effective with less manipulation [3], and can be used to diagnose and treat the lateral wall abnormalities of the nose at the same sitting [4]. Many studies have demonstrated the interest of endoscopy [5], but few involved comparisons with conventional septoplasty [4-6].

In the present study, we aimed to assess the nasal obstruction with conventional and endoscopic septoplasty, confirming our results with preoperative and postoperative computed tomography (CT) and Nasal Surgical Questionnaire (NSQ). There are many questionnaires available, such as the 'Nasal

This is an open access journal, and articles are distributed under the terms of the Creative Commons Attribution-NonCommercial-ShareAlike 4.0 License, which allows others to remix, tweak, and build upon the work non-commercially, as long as appropriate credit is given and the new creations are licensed under the identical terms. 
Obstruction Symptom Evaluation (NOSE) Scale' published by Stewart et al. [7], which considered items related to nasal symptoms, whereas others also consider general quality of life items, such as quality of life questionnaire published by Thiago et al.[8]. In the present study, we want to focus on the presurgical and postsurgical results; hence, we preferred a questionnaire that specifically assesses nasal symptoms, such as the NSQ. The NOSE questionnaire has been validated and used in many countries [9].

\section{Patients and methods}

This study was carried out on 100 patients complaining of nasal obstruction; fifty underwent endoscopic septoplasty (group A) while the other fifty underwent conventional septoplasty (group B). Their ages ranged between 16.34 (the mean age was 24.30 \pm 9.59 years) and 19.38 (the mean was $25.70 \pm 6.26$ years) in group $\mathrm{A}$ and $\mathrm{B}$, respectively. The female patients numbered 22 and 32 while the male patients numbered 28 and 18 in group $\mathrm{A}$ and B, respectively. They attended the ENT department outpatient clinics at Al-Azher University Hospitals, Egypt. The study was conducted from April 2014 to February 2018. Patients with symptoms of allergic rhinitis and those with a history of previous septoplasty/turbinate surgery were excluded. Nasal obstruction was the chief complaint in this study. History of hyposmia, nasal discharge, epistaxis, headache, and previous trauma to the nose were recorded. All procedures performed in the study involving human participants were in accordance with the ethical standards of the institutional and/or national research committee and with the 1964 Helsinki declaration and its later amendments or comparable ethical standards.

On examination, they had a septal deviation with inferior turbinate hypertrophy, which was documented by preoperative $\mathrm{CT}$ scan of the nose and parnasal sinuses. The CT scans of the paranasal sinuses were performed with $3 \mathrm{~mm}$ slice thickness in the coronal plane. The volume of the hypertrophied inferior turbinate was measured by multiplying three measurements (a) the maximum width of the turbinate in the coronal plane in an $\mathrm{mm}$, (b) the maximum height of the turbinate in the coronal plane in an $\mathrm{mm}$, (c) the maximum length of the turbinate in axial plan in an $\mathrm{mm}$ [10]. Septoplasty under general anesthesia was carried out for all the patients without turbinate surgery. Endoscopic septoplasty was performed for group A, while the standard technique, conventional septoplasty, was performed for group B by random selection.

\section{Endoscopic septoplasty}

(1) A hemitransfixation incision on the concave side was made $2 \mathrm{~mm}$ posterior to the caudal end of the septum to expose the bony cartilaginous junction for any abnormalities. The incision was made anterior to the spur in the isolated bony spur.

(2) The initial mucoperichondrial flap was elevated by an elevator and nasal speculum. This was followed by using a $0^{\circ}$ rigid nasal endoscope $(4 \mathrm{~mm})$, in the left hand, and the tip of the endoscope between the mucoperichondrial flap and the septal cartilage, while the right hand was used for instrumentation.

(3) In an obvious anterior deviation, we started the traditional technique and then treated the posterior deformities endoscopically; the correct cleavage plane was made to avoid bleeding. Exposure was limited to the target area.

(4) At the anterior nasal spine, the excess cartilage was resected inferiorly, without dislocating the vomerochondral junction, and repositioned over the crest to prevent a supratip deformity.

(5) The vomerine spur or prominent crest overlapping cartilage was resected.

(6) In case of a posterior deviation or a deviation at the vomerochondral junction, a minimal resection of the caudal end of the ethmoidal plate was performed.

(7) In the ' $\mathrm{C}$ ' shaped deviation, multiple wedge resections were carried out to place them as straight as possible.

(8) The caudal dislocation of the cartilage was corrected after correcting the rest of the septum.

(9) The incision of the mucocutaneous junction, if performed, was sutured with 3-0 vicryl.

(10) Nasal packs were applied for $24 \mathrm{~h}$ after the surgery. Further to its removal, suction of bloody discharge and saline nasal douching was advised for a week.

\section{Conventional septoplasty}

The technique used was similar to that used by Gupta and Motwani [11].

All the patients were discharged with a mentioned recommendation on the third postoperative day. Follow-up, thereafter on the seventh day and monthly for 6 months for assessment of the following was carried out.

(1) Symptoms including nasal obstruction, headache, nasaldischarge, hyposmia, posts nasal discharge. 
Table 1 Demographic data of age, sex, and type of deviation in group $A$ and $B$

\begin{tabular}{lcc}
\hline Demographic data & Group A $[n(\%)]$ & Group B $[n(\%)]$ \\
\hline Age (years) & & \\
Range & $16-34$ & $19-38$ \\
Mean \pm SD & $24.30 \pm 6.29$ & $25.70 \pm 6.26$ \\
Sex & & \\
Female & $22(44)$ & $18(36)$ \\
Male & $28(56)$ & $32(64)$ \\
Type of deviation & & \\
S shaped & $16(32)$ & $12(24)$ \\
C shaped & $20(40)$ & $22(44)$ \\
Septal spur & $14(28)$ & $16(32)$ \\
\hline
\end{tabular}

Table 2 Size of the inferior turbinate before and after septoplasty between group A and B

\begin{tabular}{lcc}
\hline $\begin{array}{l}\text { Size of the inferior } \\
\text { turbinate }\left(\mathrm{mm}^{3}\right)\end{array}$ & $\begin{array}{c}\text { Group A (mean } \\
\pm \mathrm{SD})\end{array}$ & $\begin{array}{c}\text { Group B (MEAN } \\
\pm \mathrm{SD})\end{array}$ \\
\hline Preoperative & $3.12 \pm 1.20$ & $3.88 \pm 0.12$ \\
Postoperative & $2.63 \pm 1.51$ & $2.99 \pm 1.99$ \\
Total reduction & $0.813 \pm 0.03$ & 0.769 \\
$t$-Test & 6.249 & 4.931 \\
$P$ value & 0.001 & 0.001 \\
\hline
\end{tabular}

Figure 1

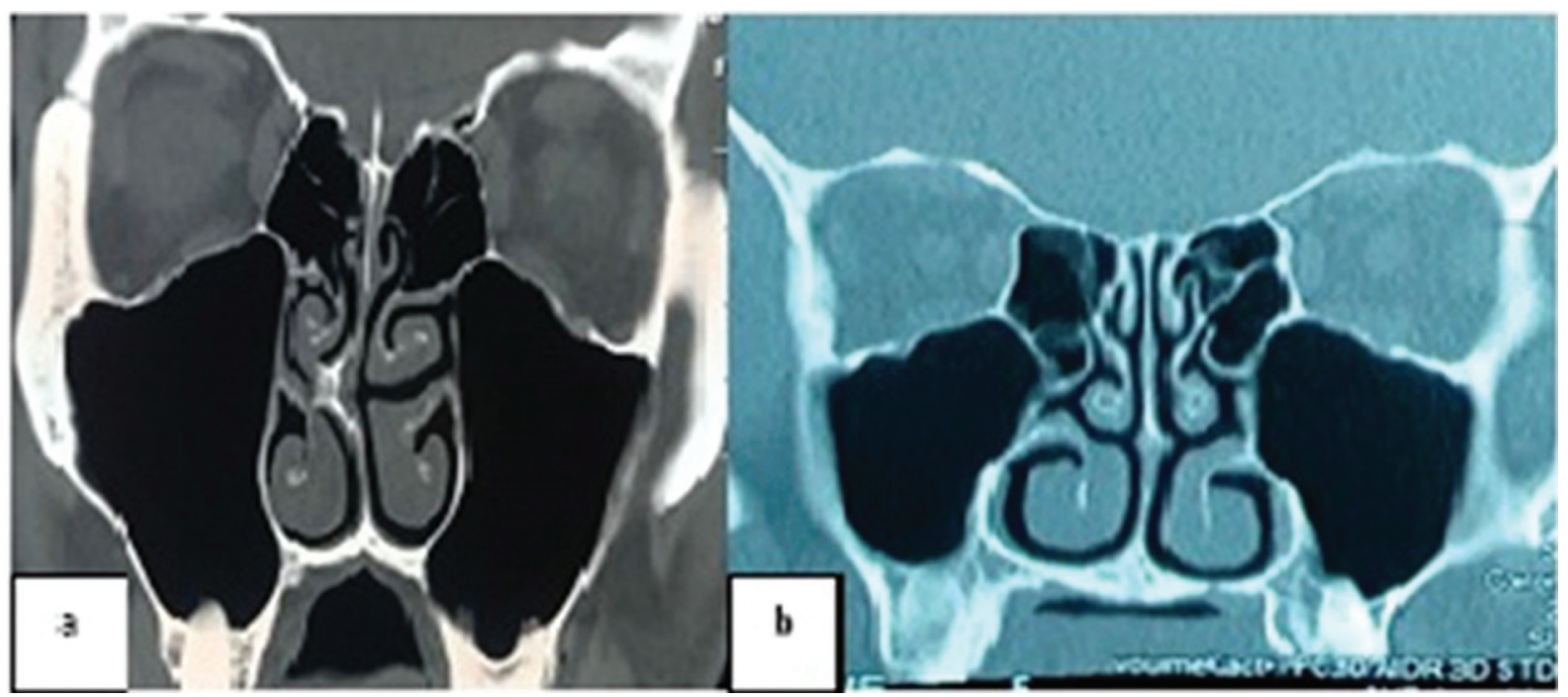

Preoperative (a) and postoperative (b) computed tomography in group A showing starting of the nasal septum and reduction of the size of the inferior turbinate.

Figure 2

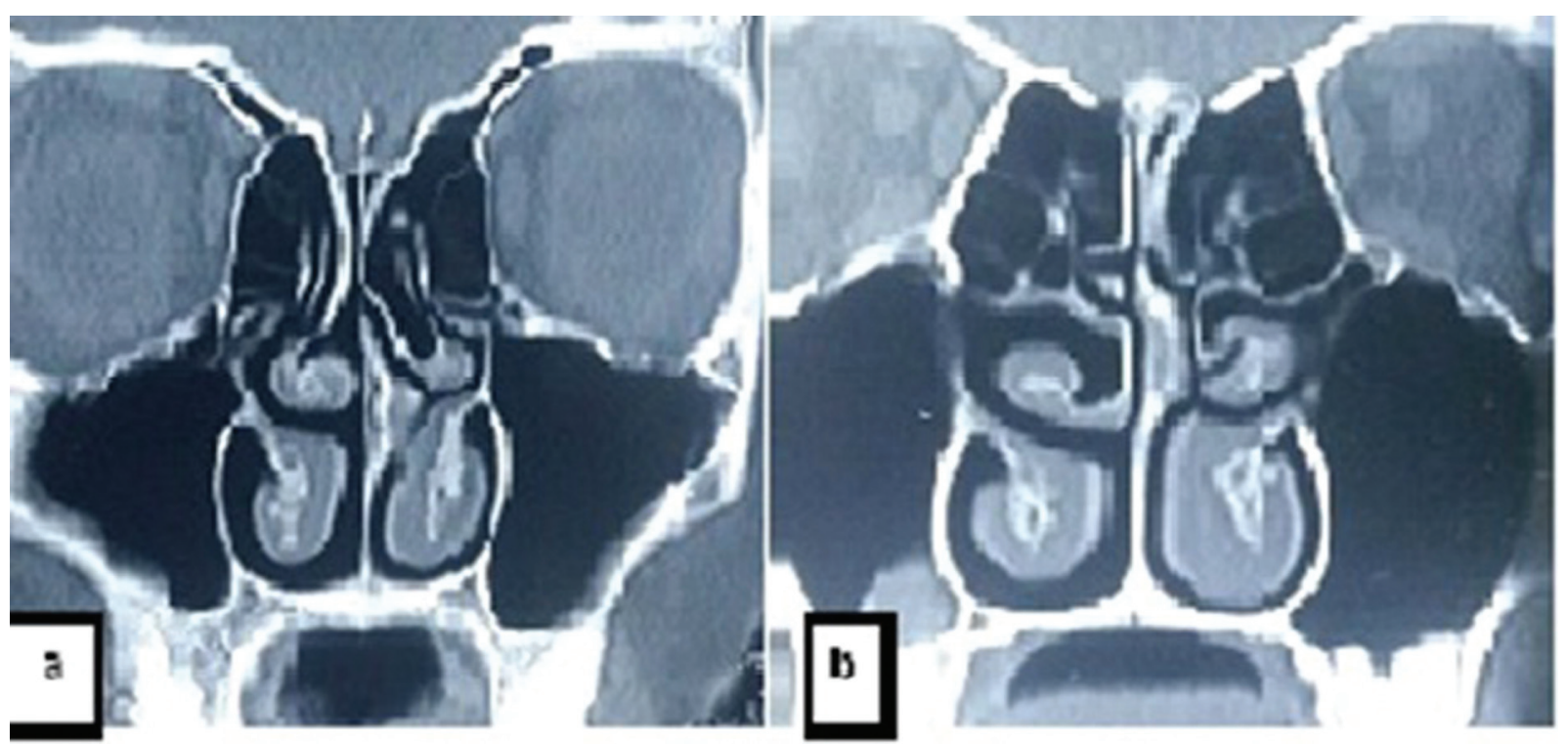

Preoperative (a) and postoperative (b) computed tomography in group B showing starting of the nasal septum and reduction of the size of the inferior turbinate. 
Objective assessment was carried out by Gertner-Podoshin plate and diagnostic nasal endoscopy.

(2) CT scan and NSQ score were carried out and assessed after six months. Postoperative CT scans at the same measurement were taken. The sheet for NSQ was provided for the 100 patients. The patients were asked to mark their sense of obstruction on this scale. There are four points ( $1=$ no, $2=$ mild, $3=$ moderate, and $4=$ severe). The postoperative NSQ is supplemented with the following five-point nasal parameters: nasal congestion or stuffiness, nasal blockage or obstruction, trouble breathing through my nose, trouble sleeping, and unable to get enough air through my nose during exercise or exertion. Patients were asked to answer the questionnaire based on a normal day without nasal infection. The total score was then multiplied by 5 for a maximum score of 100 , with 0 being asymptomatic and 100 being the worst case [8]. Dividing the group into four classes of severity and integrating the threshold resulted in the following classes and ranges: 0 mild (range: 5-25), moderate (range: 30-50), severe (range: 55-75), and extreme (range: 80-100) nasal obstruction [9].

\section{Statistical analysis}

Data were analyzed using statistical program for the social sciences (SPSS; SPSS Inc., Chicago, Illinois, USA) version 20.0. Quantitative data were expressed as mean \pm SD. Qualitative data were expressed as frequency and percentage. The following tests were

Table 3 Comparison between values of Nasal Surgical Questionnaire before and after septoplasty in group A and B using paired $t$-test

\begin{tabular}{lcc}
\hline NSQ score & Group A $($ mean \pm SD $)$ & Group B (mean \pm SD) \\
\hline Preoperative & $86.9 \pm 6.7$ & $83.12 \pm 3.88$ \\
Postoperative & $40.88 \pm 14.18$ & $48.22 \pm 15.10$ \\
Total reduction & $58.17 \pm 15.63$ & $50.99 \pm 11.7$ \\
$t$-Test & 6.553 & 4.052 \\
$P$ value & 0.001 & 0.001 \\
\hline
\end{tabular}

carried out: Paired sample $t$-test of significance was used when comparing between related samples.

\section{Results}

The demographic data of the 100 patients with nasal deviation are summarized in Table 1.

With regard to the size of the inferior turbinates, there was a significant reduction on the postoperative size of the inferior turbinate $(P=0.001)$, as shown in Table 2 , Figs 1 and 2.

With regard to the nasal obstruction, postoperative NSQ score decreased significantly in both groups $(P<0.001)$; however, group A showed a better reduction than group $\mathrm{B}$ (Table 3 ).

As regards the other nasal symptoms, there was a significant improvement of the postoperative nasal discharge in both groups $(P=0.0001)$, while postoperative headache, snoring, hyposmia, and epistaxis showed insignificant improvement. History of nasal trauma was found in six patients. Postoperative assessment of the patients as regards the other nasal symptoms are shown in Table 4, Fig. 3.

\section{Discussion}

The results of a classic corrective technique for septoplasty depends on the feeling sensed by the surgeon's hand; hence, endoscopic-assisted septoplasty can overcome these drawbacks [12]. This prospective study included 100 patients; 50 underwent endoscopic septoplasty while the other 50 underwent conventional septoplasty. We evaluated the nasal symptomology (mainly nasal obstruction). We documented our results by CT scan and NSQ.

In this study, with regard to age and sex (Table 1), the mean age of the patients in group A was $24.30 \pm 9.59$ years while in group B it was $25.70 \pm 6.26$. This was close to the mean age of the patients in the study by Gandomi et al. [13], in which the mean age was 22.4 years. They referred to more benefit of correcting only

Table 4 Comparison between other nasal symptomatology before and after septoplasty in group A and B

\begin{tabular}{|c|c|c|c|c|c|c|}
\hline \multirow[t]{2}{*}{ Symptoms } & \multicolumn{2}{|c|}{ Group A [n (\%)] } & \multirow[t]{2}{*}{$P$ value } & \multicolumn{2}{|c|}{ Group B $[n(\%)]$} & \multirow[t]{2}{*}{$P$ value } \\
\hline & Preoperative & Postoperative & & Preoperative & Postoperative & \\
\hline Nasal discharge & $50(100)$ & $13(26)$ & 0.0001 & $50(100)$ & $14(28)$ & 0.0001 \\
\hline Headache & $15(30)$ & $5(10)$ & 0.106 & $26(52)$ & $10(20)$ & 0.113 \\
\hline Snoring & $10(20)$ & $4(8)$ & 0.184 & $15(30)$ & $10(20)$ & 0.184 \\
\hline Hyposmia & $4(8)$ & $2(6)$ & 0.405 & $5(10)$ & $4(8)$ & 0.405 \\
\hline Epistaxis & 0 & 0 & & 0 & 0 & \\
\hline
\end{tabular}


Figure 3

-Group A (\%) Preoperative \%

I Group A (\%) Postoperative \%

II Group B (\%) Preoperative \%

-Group $B(\%)$ Postoperative \%

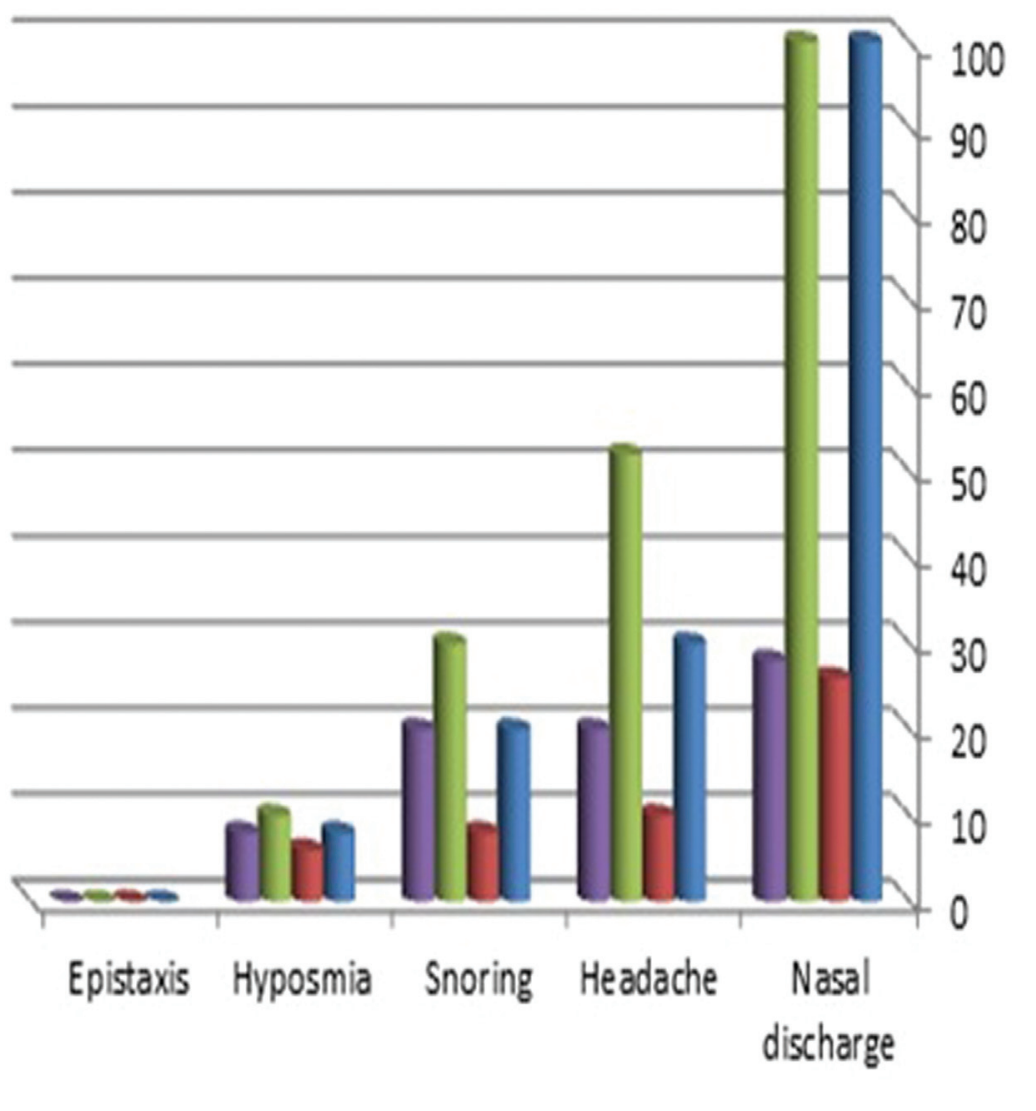

Preoperative and postoperative other nasal symptomatology in groups A and B.

the anatomical cause of nasal obstruction in young age, while in older patients, dynamic causes are more important, as reported by Stewart et al. [7], who conducted their study on 62 patients with a mean age of 44.7 years. Those patients, besides septal deviation, had complained of allergic rhinitis, and they reported success rates of $63 \%$ only.

In this study, the male patients numbered 28 (56\%) and 32 (64\%) in group A and B, respectively; this higher incidence in male patients was close to the findings of the study by Behnoud et al. [14] which showed 70\% male predominance, explained by the fact that male patients are more prone to nasal trauma.

In this study, the mean thickness of the entire dimension of the inferior turbinates after septoplasty in both groups was significantly decreased $(P=0.001)$. However, group A showed a better reduction than group B (Table 2). This is in agreement with Sathyaki et al. [4] who showed that hypertrophy of turbinates was present only in one of the twelve patients in endoscopic septoplasty, while it was present in three of the eleven patients in the conventional septoplasty group.
In this study, NSQ score showed highly significant postoperative decrease in both groups $(P=0.001)$, but group A showed more reduction than B (Table 3). This in agreement with Paradis and Rotenberg [6] who recorded postoperative improvements in the NOSE scores within both groups (endoscopic: preoperative mean score $=14.7$, postoperative mean score $=7.4, P<0.05$; conventional: preoperative mean score $=15.2$, postoperative mean score $=6.3, P<0.05$ ), with no differences found between the groups $(P=0.61)$. Sathyaki et al. [4], assessed nasal patency in 63 patients (32 in the endoscopic group and 31 in the conventional group) using Gertner-Podoshin plate, and the results were similar, as the difference in improvement was insignificant.

In this study, the other nasal somatology showed significant improvement of the postoperative nasal discharge in both groups $(P=0.0001)$, while postoperative headache, snoring, hyposmia and epistaxis showed insignificant improvement (Table 4, Fig. 3). These results were relatively different to the study by Sathyaki et al. [4], who found significant improvement in symptoms in both 
the groups when compared with preoperative symptomatology.

In this study, no obvious complications were observed in group $A$, while in group B, complications were limited to synechae which persisted in one case, infraorbital edema in two cases and residual nasal deviation in six cases. These results were in agreement with Gulati et al. [15], who reported that there was a statistically significant difference between the two groups as regards nasal obstruction, headache, recurrent rhinorrhea, hyposmia, and postnasal drip $(P<0.05)$. In contrast, our results were markedly better than Park et al. [12], who reported 0\% complication in endoscopic correction while 14.3\% complications were observed in conventional septoplasty. The study conducted by Bothra et al. [16], also reported minor complications like hemorrhage, infraorbital edema and nasal pain in conventional septoplasty patients, while Synechae persisted in two patients of each group.

\section{Conclusion and recommendation}

Endoscopic septoplasty had better results when compared with conventional septoplasty, in deviated nasal septum associated with nasal obstruction, as documented with CT scan and NSQ score.

\section{Financial support and sponsorship} Nil.

\section{Conflicts of interest}

There are no conflicts of interest.

\section{References}

1 Acar B, Yavuz B, Karabulut H, Gunbey E, Babademez MA, Yalcin AA, et al. Sympathetic overactivity in patients with nasal septum deformities. Eur Arch Otorhinolaryngol 2010; 267:73-76.

2 Lalwani AK. Current diagnosis \& treatment in otolaryngology - head \& neck surgery: introduction, anatomy of nose \& sinuses, Access Medicine 2012; 3. https://accessmedicine.mhmedical.com/book.aspx?bookID=386.

3 Getz AE, Hwang PH. Endoscopic septoplasty. Curr Opin Otolaryngol Head Neck Surg 2008; 16:26-31.

4 Sathyaki DC, Geetha C, Munishwara GB, Mohan M, Manjuanth K. A comparative study of endoscopic septoplasty versus conventional septoplasty. Indian J Otolaryngol Head Neck Surg 2014; 66:155-161.

5 Chung BJ, BatraPS, Citardi MJ, Lanza DC. Endoscopic septoplasty: revisitation of the technique, indications, and outcomes. Am J Rhinol 2007; 21:307-311.

6 Paradis J, Rotenberg BW. Open versus endoscopic septoplasty: a singleblinded, randomized, controlled trial. J Otolaryngol Head Neck Surg 2011; 40:28-33.

7 Stewart MG, Smith TL, Weaver EM, et al. Outcomes after nasal septoplasty: results from the Nasal Obstruction Septoplasty Effectiveness (NOSE) Study. Otolaryngol Head Neck Surg 2004; 130:283-290.

8 Bezerra TFP, Stewart MG, Fornazieri MA, de Mendonca Pilan RR, de Rezende Pinna F, de Melo Padua FG, et al. Quality of life assessment septoplasty in patients with nasal obstruction. Braz J Otorhinolaryngol 2012; 78:3.

9 Haye R, Tarangen M, Shiryaeva O, Dosen LK. Evaluation of the nasal surgical questionnaire for monitoring results of septoplasty. Int J Otolaryngol 2015; 2015:563639. https://www.hindawi.com/journals/ijoto/2015/563639/

10 Raheem AGA, Salem MAM, Mohammed MZ. Does septoplasty affect the size of compensatory hypertrophy of the inferior turbinates in deviated nasal septum? AAMJ 2015; 13(Suppl 1):129-138.

11 Gupta M, Motwani G. Comparative study of endoscopic aided septoplasty and traditional septoplasty in posterior nasal septal deviations. Indian Otolaryngol Head Neck Surg 2005; 57:309-311.

12 Park DH, Kim TM, Han DG, Ahn KY. Endoscopic-assisted correction of deviated nose. Aesthetic Plast Surg 1998; 22:190-195.

13 Gandomi B, Bayat A, Kazemei T. Outcomes of septoplasty in young adults: the nasal obstruction septoplasty effectiveness study. Am J Otolaryngol 2010; 31:189-192.

14 Behnoud F, Nasab MS, Alizamir A. Comparison of the frequency of old septal deviation in patient with and without traumatic nasal bone fracture. Acta Medica Iranica 2010; 48:304-307.

15 Gulati SP, Wadhera R, Ahuja N, Garg A, Ghai A. Comparative evaluation of endoscopic with conventional septoplasty. Indian J Otolaryngol Head Neck Surg 2009; 61:27-29.

16 Bothra R, Mathur NN. Comparative evaluation of conventional versus endoscopic septoplasty for limited septal deviation and spur. J Laryngol Otol 2009; 123:737-741. 